nuisance caused by noise at a distance from a factory may be due to sources which are not apparent inside or in its immediate environment.

Handling noises can often be much reduced by using plastic- or rubber-covered benches and bins; delivery chutes should be smooth inside and designed to avoid too great a distance of fall into bins.

Sound insulation or absorption is employed when a noisy source cannot be eliminated. An insulating barrier may absorb or reflect sound. The process of absorption involves the dissipation of sound energy as heat and takes place either by the barrier itself vibrating or by the vibrating air inside cavities in porous insulation wasting its energy as friction.

The sound insulation of a partition is expressed by its sound reduction index, which is the difference between the sound pressure-levels on the incident and transmitted sides. There is a good correlation between the index and the weight per square foot for homogeneous sheet materials. Best results are obtained with isolated panels separated by an air gap. In general, high-pitched sounds are likely to have a greater sound reduction index than lowpitched ones, for which weight of insulator is the predominating factor. Irregularities of transmission are more common at higher frequencies.

If a machine is totally enclosed in reflective insulation the sound-level inside will build up. Absorption is necessary as well. The best absorbers are porous materials, such as mineral wool; though thin layers are effective at high frequencies, large thicknesses become necessary at low. When a very high degree of sound insulation is required small leaks through a partition must be avoided. A sound-reduction index of 40 decibels means that only 1 part in $10^{4}$ of the incident sound energy is transmitted. An aperture with an area of only $1 / 10,000$ of that of the insulated partition will let through as much sound as the entire partition. When apertures have to be made they can be provided with sound-attenuating ducts, which are also of value in ventilating systems to eliminate fan noise. The principle of such ducts is absorption at the wall, and their efficiency is increased by subdivision into a number of narrow channels. Noise reduction in decibels is proportional to the length. Attenuation increases with frequency up to a point at which the wave length of the sound is equal to the channel width.

Anti-vibration mountings are of value in reducing noise transmitted from machines; they should be designed so that the natural frequency of the machine on its resilient supports is much lower then that of the objectionable vibration. Complaints are sometimes aroused by low-frequency pulsation, as from engine exhausts. The fitting of an expansion chamber about
15 times the volume swept by the piston at each stroke and an absorbent wall silencer had been helpful in such cases.

The final paper, read by Dr. Alan Carpenter (Medical Research Council Applied Psychology Research Unit, Cambridge), deslt with the question whether noise which was not loud enough either to produce actual physical damage or to arouse annoyance could yet be responsible for interference with mental work.

An experiment performed a quarter of a century ago indicated that the output of work from weavers was increased very slightly when they wore ear plugs which reduced the noise transmitted by 10-15 decibels, in spite of the fact that the workers did not like using the ear plugs and thought they were of no value. More than fifty years ago it had been demonstrated that a slowing down of performance was produced every time an intermittent noise was turned on or off, with a return to a normal speed of working between times.

Noise which had meaning was more distracting than meaningless sound, especially if the meaning was a little elusive. It was probable, too, that noise was more disturbing to a worker engaged on a task with which he was not very familiar.

Recent work had resulted in the formulation of the hypothesis of the 'mental blink', which had some analogy with eye blinking. Experiments suggested that effective regulating mechanisms existed in man which tended to maintsin his output quality in spite of disturbing influences. They were analogous to feed-back in physical servo systems or to the maintenance of arterial blood pressure and other physiological devices. When such a mechanism operated it was unprofitable to look for changes of output resulting from external stimuli ; it was better to examine the signal process or to seek for some aspect of the behaviour of the system outside its regulation. The 'mental blink', or a shifting away and shifting back of attention upon a mental task, provided such an opportunity. A subject in a good state of motivation would bring his attention back to a monotonous task in one and a half to two seconds. Attention could not be constantly held but tended to wander.

It was probable that in a watch-keeping job, where slackening of attention could result in an expensive mishap, a strong case existed for excluding loud noise. In inspection, too, where lapses of vigilance would increase the number of incorrect articles to be accepted, loud noises should be eschewed.

A full account of the Conference will be published in the first issue of the Society's journal, Annals of Occupational Hygiene.

C. N. Davies

\title{
OBITUARIES
}

\section{Dr. C. E. P. Brooks, I.S.O.}

W'rTH the death of Dr. C. E. P. Brooks on December 14, climatology in Britain lost its most eminent authority and the meteorological profession one of its most versatile members.

Dr. Brooks was born in London on November 10 , 1888. He was educated at University College School, London, and entered the Meteorological Office as a probationer in 1907. Studying in his own time, he graduated B.Sc. (London) with honours in geology in
1912. He proceeded to M.Sc. in 1916, and in 1926 the D.Se. was awarded to him for a thesis on "The Variations of Pressure in the Neighbourhood of the British Isles".

$\mathrm{He}$ served in the Meteorological Office for more than forty years, retiring in 1948 as assistant director (climatology), though he continued part-time work for the Office, mainly on the application of statistical methods in meteorology, for a further two years. Shortly before retiring, he was made a Companion of the Imperial Service Order. 
Brooks's major scientific work was, appropriate to his training, the study of past climates, on which he was an authority of world renown. His main conclusion in this field, expounded in many papers and in his two books on the subject, "The Evolution of Climate" (1922) and "Climate through the Ages" (1926, second edition 1949), was that the major climatic variations were explicable on the solely geographical grounds of changes in the distribution of land and sea, of relief, and ocean currents. $\mathrm{He}$ recognized the importance of the astronomical factor of changes in the intensity of insolation due to variations in the Sun's radiation and in the Earth's orbit, but considered this as responsible for only the relatively short-period and minor climatic fluctuations. The great ice ages he considered to be disturbances in the generally mild climate of the Earth's history which were associated with the periods of great mountain-building (Caledonian, Alpine, etc.). These conclusions were reached from a profound statistical study of the relation of climate to the distribution of land and sea and ice-cover.

This statistical work made him the leading British expert in statistical meteorology, a subject in which his deep knowledge and skill are shown by his last book, the "Handbook of Statistical Methods in Meteorology", written with Miss Nellie Carruthers (Mrs. A. H. R. Goldie) and published for the Meteorological Office by H.M. Stationery Office in 1953. $\mathrm{He}$ did much, also, on the subjects of seasonal forecasting and solar-terrestrial relations, and, more recently, on the distribution of upper winds ; and he showed great ingenuity in the solution of the problems which come to the Meteorological Office on the application of meteorology to economic and industrial affairs. In the last-mentioned field his book, "Climate in Everyday Life" (1950), is a valuable account of the use of meteorology in many spheres from agriculture to the design of buildings and packing-cases. For twenty-two years he was editor of the Meteor. ological Magazine.

He was for long the world's leading meteorological bibliographer. He made the Meteorological Office Library, of which he was for many years in charge, a great storehouse of knowledge, comprehensively and exactly recorded, and completely recast the meteorological section of the Universal Decimal Classification to fit it for the accurate recording of the great new increases in knowledge of the past forty years. $\mathrm{He}$ represented the Office on the Climatological and Bibliographical Commissions of the International Meteorological Organization and attended several meetings of those bodies.

Brooks served the Royal Meteorological Society, of which he was Buchan prizeman in 1931, as honorary secretary, librarian, vice-president and councillor, holding one or more of these offices almost continuously from 1916 until 1948. The Society's Quarterly Journal published more than sixty original papers of which he was sole or part author. After retiring, he collaborated in the production of the American Meteorological Society's Meteorological Abstracts and Bibliography, and contributed to it some ten thousand abstracts of British and German articles.

Brooks was a man of great energy and enthusiasm which were by no means used solely in scientific work. He played at first board for the Air Ministry Chess Club for many years and was an enthusiast for bridge, lawn tennis and swimnaing. Memorable, too, is his care for the welfare of his staff, notably in the difficult dispersal of war-time.

$\mathrm{He}$ married in 1916 Miss Dora Buckeridge, then a colleague in the Office, and she survives him with their son.

G. A. BuLL

\section{Dr. T. A. Henry}

Thomas Anderson Henry died in Fulham Hospital, London, on May 4 at the age of eighty-five, after a fall at his home. He was born in Dundee on January 20, 1873, but received his early education in Barrow-in-Furness. Like many of his generation, he started his chemical career through pharmacy. After serving his apprenticeship, he moved to London in 1893, when he was awarded the senior Jacob Bell scholarship and passed the Minor and Major Examinations of the Pharmaceutical Society in 1895. The following two years he spent in the Society's research laboratories while holding the Redwood and Manchester scholarships.

In 1896 Dr. Henry was appointed to the scientific research staff of the Imperial Institute, and ultimately became superintendent of laboratories. During this fruitful period at the Imperial Institute he held a Salters Research Fellowship and was awarded the D.Sc. degree of the University of London. During this time, also, he became interested in, and examined, a large number of natural products of economic and scientific importance, among which were cyanogenetic glycosides and alkaloids. With the late Sir Wyndham Dunstan he published more than a dozen papers on cyanogenetic glycosides. He also began writing the book by which he will long be remembered, "The Plant Alkaloids". First published in 1913, the book was until quite recently unrivalled and reached the fourth edition in 1949. Even to-day, nine years after publication, this edition is still widely used and quoted.

In 1919 Dr. Henry left the Imperial Institute to succeed the late Prof. F. L. Pyman as director of the Wellcome Chemical Research Laboratories, a post which he retained until his retirement in 1943. While maintaining his interest in alkaloids, on which he published many papers and inspired others, he developed an interest in chemotherapy, particularly in relation to tropical diseases.

In the laboratory, Dr. Henry was a strict disciplinarian; a meticulous worker himself, he expected a similar high standard from his staff. He could be especially severe with slipshod writing, for he himself was a master of the exact word and apt phrase. But 'off parade' there emerged a charming, modest and kindly man with the interests and welfare of his staff much at heart; many of his technicians owe to him their first chance of advancement. Dr. Henry was of considerable literary erudition, had wide cultural interests and was fond of drama and the theatre. He was much interested in paintings and spent many holidays in Europe visiting art galleries.

In 1927 Dr. Henry was awarded the Hanbury Memorial Medal "for high excellence in the prosecution of research". He was a vice-president of the Chemical Society, served on its Council and Publications Committee and was chairman of the Library Committee. He also served on committees of the British Pharmacopcia Commission and the British Pharmaceutical Codex. He was an original member of the Biochemical Society.
T. M. SHARP 